\title{
RESEARCH LETTER
}

\section{Regional Variation in DLQI 0/1 Within the CorEvitas Psoriasis Registry 6-months Following Biologic Initiation}

\author{
Clinton W. Enos, MD, MS ${ }^{1}$, Katie A. O'Connell, MS ${ }^{1}$, Ryan W. Harrison, $\mathrm{MS}^{2}$, Robert R McLean, \\ DSc, $\mathrm{MPH}^{2}$, Blessing Dube, $\mathrm{MPH}^{2}$, Abby S. Van Voorhees, MD${ }^{1}$ \\ ${ }^{1}$ Eastern Virginia Medical School Department of Dermatology, Norfolk, VA \\ 2 CorEvitas, LLC, Waltham, MA
}

Recently, we identified geographic variation in treatment patterns and outcomes among psoriasis patients across the United States (US) enrolled in the CorEvitas Psoriasis Registry. ${ }^{1}$ As there is a predictive correlation between reductions in psoriasis area severity index (PASI) and the Dermatology Life Quality Index (DLQI) scores among psoriasis patients treated in clinical trials with biologics, ${ }^{2}$ we assessed for geographic differences in achieving DLQI 0/1 among US patients initiating a biologic therapy in 2018 in the CorEvitas Psoriasis Registry, a multicenter registry of psoriasis patients under the care of a dermatologist. Informed consent of human subjects was obtained.

There were 737 new biologic initiations (mean age 50.3 years, $48.0 \%$ women) in 2018 occurring at a CorEvitas visit that had a subsequent 6-month follow-up, 644 of whom had DLQI > 0 at baseline. ${ }^{1}$ Baseline mean DLQI scores did not vary significantly among geographic regions, $p=0.072$ (Table I). Overall, $42.7 \%$ of patients achieved DLQI 0/1 at 6-months. The Pacific region reported the smallest proportion achieving this target (26.9\%) followed by the East South Central (ESC) $(34.3 \%)$ and West South Central (WSC) $(40.9 \%)$ with a range of $26.9-51.1 \%$ across all regions $(p=0.005)$. In logistic regression models adjusted for age, sex, race, and $\mathrm{BMI}$, the Pacific had $61 \%$ lower odds of achieving DLQI 0/1 compared to the Northeast (Odds Ratio 0.39, 95\% Cl: 0.21 0.71) (Table I). In analyses stratified by biologic therapy class, patients in the Pacific and the ESC were less likely to achieve DLQI $0 / 1$ compared to the Northeast among IL12/23 \& IL-23 inhibitor initiators (OR 0.23, 95\% Cl: 0.08-0.65 and 0.23, 95\% Cl: 0.070.76 , respectively) (Table II).

As patient-reported-outcomes become more commonplace, consistent monitoring of DLQI will be increasingly important. In a number of countries, DLQI is now part of reimbursement eligibility criteria. ${ }^{3}$ Previous work has shown that DLQI scores are directly associated with measures of disease severity and parallel treatment response. ${ }^{2}$ Our prior study found that patients in the ESC, WSC, and Pacific regions were less likely to achieve PASI75 compared to the Northeast (the region with the greatest proportion of patients achieving treatment targets). ${ }^{1}$ These geographic regions also had the lowest proportion of patients achieving DLQI 0/1 at the 6-month follow-up visit, consistent with prior observed correlations between these outcome 
Table 1. Baseline DLQI and odds ratios (95\% CI) for achieving DLQIO/1 response at 6-months follow-up by US Census region in the Corrona Psoriasis Registry, 2018

\begin{tabular}{|c|c|c|c|c|}
\hline \multirow[t]{2}{*}{ Region } & \multicolumn{2}{|c|}{ DLQI at Baseline ${ }^{1}$} & \multicolumn{2}{|c|}{ DLQI0/1 Response at 6-months } \\
\hline & $\begin{array}{l}\text { Mean } \\
\text { (SD) }\end{array}$ & $\underset{\text { Q3) }}{\text { Median }}($ Q1, & $\%$ (Responders/total) & Adjusted OR $(95 \% \mathrm{Cl})^{2}$ \\
\hline Northeast & $8.1(6.2)$ & $6.0(3.0,12.0)$ & $45.7(90 / 197)$ & Ref \\
\hline Pacific & $9.0(5.6)$ & $9.0(4.0,14.0)$ & $26.9(25 / 93)$ & $0.39(0.21,0.71)^{\star *}$ \\
\hline $\begin{array}{l}\text { Mountain/West North } \\
\text { Central }\end{array}$ & $6.9(5.6)$ & $5.5(2.2,10.8)$ & $49.4(39 / 79)$ & $1.15(0.68,1.96)$ \\
\hline West South Central & $8.7(5.8)$ & $8.0(4.0,12.0)$ & $40.9(18 / 44)$ & $0.92(0.47,1.82)$ \\
\hline East North Central & $7.1(5.6)$ & $5.5(2.0,11.0)$ & $51.1(24 / 47)$ & $1.26(0.64,2.47)$ \\
\hline East South Central & $7.5(6.0)$ & $6.5(3.0,11.0)$ & $34.3(34 / 99)$ & $0.71(0.42,1.19)$ \\
\hline South Atlantic & $7.2(5.8)$ & $5.5(3.0,10.0)$ & $52.9(45 / 85)$ & $1.47(0.86,2.51)$ \\
\hline Overall & $7.8(5.9)$ & $7.0(3.0,12.0)$ & $42.7(275 / 644)$ & -- \\
\hline
\end{tabular}

Table 2. Odd ratios $(95 \% \mathrm{Cl})$ for achieving DLQI response 6-months following biologic initiation for US Census regions in the Corrona Psoriasis Registry in 2018 , stratified by biologic class

\begin{tabular}{|c|c|c|c|c|c|c|}
\hline & & & IL- & & IL-12/: & i+IL-23i \\
\hline Region & $\begin{array}{c}\% \\
\text { (Responders/t } \\
\text { otal) }\end{array}$ & $\begin{array}{l}\text { Adjusted OR } \\
(95 \% \mathrm{Cl})^{1}\end{array}$ & $\begin{array}{c}\% \\
\text { (Responders/t } \\
\text { otal) }\end{array}$ & $\begin{array}{c}\text { Adjusted } \\
\text { OR (95\% } \\
\text { Cl) })^{1}\end{array}$ & $\begin{array}{c}\% \\
\text { (Responders/t } \\
\text { otal) }\end{array}$ & $\begin{array}{l}\text { Adjusted OR } \\
\qquad(95 \% \mathrm{Cl})^{1}\end{array}$ \\
\hline Northeast & $35.3(6 / 17)$ & Ref & $35.6(26 / 73)$ & Ref & $54.2(58 / 107)$ & Ref \\
\hline Pacific & $29.2(7 / 24)$ & $\begin{array}{c}0.79(0.17 \\
3.61)\end{array}$ & $24.4(11 / 45)$ & $\begin{array}{c}0.47(0.18 \\
1.21)\end{array}$ & $23.1(6 / 26)$ & $0.23(0.08,0.65)$ \\
\hline $\begin{array}{l}\text { Mountain/ } \\
\text { West North } \\
\text { Central }\end{array}$ & $45.5(10 / 22)$ & $\begin{array}{c}1.14(0.28 \\
4.56)\end{array}$ & $60.6(20 / 33)$ & $\begin{array}{c}2.38(1.00, \\
5.70)\end{array}$ & $37.5(9 / 24)$ & $0.60(0.23,1.57)$ \\
\hline $\begin{array}{l}\text { West } \\
\text { South } \\
\text { Central }\end{array}$ & $50.0(3 / 6)$ & $\begin{array}{c}1.22(0.16 \\
9.57)\end{array}$ & $47.1(8 / 17)$ & $\begin{array}{c}1.76(0.58 \\
5.34)\end{array}$ & $33.3(7 / 21)$ & $0.53(0.19,1.46)$ \\
\hline $\begin{array}{l}\text { East North } \\
\text { Central }\end{array}$ & $62.5(5 / 8)$ & $\begin{array}{c}2.09(0.32 \\
13.54)\end{array}$ & $57.1(12 / 21)$ & $\begin{array}{c}2.40(0.87 \\
6.64)\end{array}$ & $38.9(7 / 18)$ & $0.52(0.18,1.49)$ \\
\hline $\begin{array}{l}\text { East South } \\
\text { Central }\end{array}$ & $30.0(6 / 20)$ & $\begin{array}{c}0.68(0.16 \\
2.96)\end{array}$ & $40.7(24 / 59)$ & $\begin{array}{c}1.39(0.66 \\
2.90)\end{array}$ & $20.0(4 / 20)$ & $0.23(0.07,0.76)$ \\
\hline $\begin{array}{l}\text { South } \\
\text { Atlantic }\end{array}$ & $28.6(4 / 14)$ & $\begin{array}{c}0.61(0.12 \\
3.01)\end{array}$ & $55.0(22 / 40)$ & $\begin{array}{c}2.11(0.95 \\
4.71)\end{array}$ & $61.3(19 / 31)$ & $\begin{array}{c}1.54(0.65 \\
3.64)\end{array}$ \\
\hline
\end{tabular}

${ }^{1} \mathrm{OR}(95 \% \mathrm{Cl})$ from multivariable logistic regression adjusted for age, sex, race, BMI, and baseline BSA. Firth adjustments were utilized to address quasi-separation.

measures. ${ }^{2}$ Yet, after controlling for age, sex, race, and $\mathrm{BMI}$, only the Pacific was statistically significantly less likely to achieve DLQI 0/1. Reasons for inconsistency among the Pacific, ESC, and WSC with respect to odds of achieving DLQI 0/1 are not yet known. We suspect several variables may contribute, including genetic heterogeneity or January 2022 Volume 6 Issue 1 
lifestyle characteristics not captured as part of the registry.

Limitations of this study include that the CorEvitas registry is not a random, population-based, representative sample. The impact of seasonal/climate related variables, genetic heterogeneity, and dietary factors were not considered in this analysis. When analyzing outcomes by drug class in the fully adjusted model, sample sizes were small and therefore need to be interpreted with caution.

Despite these, with the use of real-world data, we show that improvement of DLQI scores at 6-months of treatment for psoriasis is not geographically uniform across the US. Regions that had the lowest proportions of achieving PASI $75^{1}$ also had the lowest proportions of patients achieving DLQI 0/1; yet when fully adjusted only patients in the Pacific region were less likely to achieve DLQI $0 / 1$, suggesting factors beyond treatment response impact patient quality of life.

Acknowledgements: The authors thank the participating providers and patients for contributing data to the CorEvitas Psoriasis Registry. This study was supported through a partnership between the CorEvitas Psoriasis Registry and the National Psoriasis Foundation Medical Board.

Conflict of Interest Disclosures: Abby S. Van Voorhees, MD receives Grant/Research Support from Celgene, Lilly, AbbVie; Consultant: Amgen, BMS, Boehringer Ingelheim, UCB

Funding: This study was sponsored by CorEvitas, LLC (formerly CorEvitas) and the analysis was funded by CorEvitas LLC. Access to study data was limited to CorEvitas and CorEvitas statisticians completed all of the analysis; all authors contributed to the interpretation of the results. CorEvitas has been supported through contracted subscriptions in the last two years by AbbVie, Amgen, Boehringer Ingelheim, Bristol-Myers Squibb, Celgene, Chugai, Eli Lilly and Company, Genentech, Gilead, Janssen,
Novartis, Ortho Dermatologics, Pfizer Inc., Regeneron, Sanofi, Sun and UCB.

Corresponding Author:

Abby S. Van Voorhees, MD

Eastern Virginia Medical School

Department of Dermatology

721 Fairfax Avenue

Suite 200, Andrews Hall

Norfolk, VA 23507

Phone: 757-446-5629

Fax: 757-446-6000

Email:vanvooas@evms.edu

\section{References:}

1. Enos CW, O'Connell KA, Harrison RW, McLean RR, Dube B, Van Voorhees AS. Psoriasis Severity, Comorbidities and Treatment Response Differ Among Geographic Regions in the United States. Under Review at: JID Innovations.

2. Mattei PL, Corey KC, Kimball AB. Psoriasis Area Severity Index (PASI) and the Dermatology Life Quality Index (DLQI): the correlation between disease severity and psychological burden in patients treated with biological therapies. J Eur Acad Dermatol Venereol. 2014;28(3):333-337. doi:10.1111/jdv.12106

3. Poór AK, Brodszky V, Péntek $M$, et al. Is the DLQI appropriate for medical decisionmaking in psoriasis patients?. Arch Dermatol Res. 2018;310(1):47-55. doi:10.1007/s00403-017-1794-4

4. Strober B, Greenberg JD, Karki C, et al. Impact of psoriasis severity on patientreported clinical symptoms, health-related quality of life and work productivity among US patients: real-world data from the CorEvitas Psoriasis Registry. BMJ Open. 2019;9(4):e027535. Published 2019 Apr 20. doi:10.1136/bmjopen-2018-027535 